\title{
Studies of reactivity of some Sri Lankan population groups to antigens of Mycobacterium leprae. II. Reactivity to a soluble protein antigen
}

\author{
M R M PINTO,* N B ERIYAGAMA* \\ \& V PEMAJAYANTHA**
}

*Department of Microbiology, Faculty of Medicine, University of Peradeniya, Peradeniya; **Division of Biometry, Central Agricultural Research Institute, Gannoruwa, Sri Lanka.

\section{Accepted for publication 14 August 1986}

\begin{abstract}
Summary This paper reports a survey of reactivity to a Soluble Protein Antigen (SPA) of Mycobacterium leprae, in two adult population groups in Sri Lanka, from two localities with widely differing geographical characteristics and levels of nonspecific mycobacterial sensitization. The patterns of reactions observed in the populations were bimodal with distinct 'reactor' and 'nonreactor' components. It was decided that the reactor and nonreactor ('positive' and 'negative' respectively), could be best demarcated in both a reas at a reaction size of $5 \mathrm{~mm}$. The mode of reactors with SPA was at $11-12 \mathrm{~mm}$.

Reactivity to SPA was found to show no statistically significant changes with age, sex, race or BCG vaccination status, while there was a possibility of differences with geographical locality.

The patterns of reactivity shown by SPA and the Fernandez reaction were different, in both areas. A likely reason for this difference was thought to be the possibility that the antigens available for eliciting the reactions in both were probably different - lepromin being whole $M$. leprae, and SPA, disrupted $M$. leprae.
\end{abstract}

\section{Introduction}

It is generally believed that the lepromin test is of little or no value in identifying infection with Mycobacterium leprae. However in other mycobacterial infections, protein antigens (e.g. purified protein derivatives) are considered to be of much greater value in identifying those infected, and are widely used as such. Recently, protein antigens of $M$. leprae have been prepared by disruption of the bacteria by various methods (Soluble Protein Antigen, SPA), and used for skin-test studies, in the hope, that such tests would be of help in identifying those infected with $M$. 
leprae. The literature with studies using these antigens is however as yet limited. We report here, a study of the patterns of reactivity observed in two population groups in Sri Lanka, to such a SPA, prepared by Dr RJW Rees of the Clinical Research Centre, Harrow, Middlesex, England.

\section{Materials and methods}

The populations investigated were from two geographically different areas, at Mahagastota and Galagedera, selected for the known and expected differences in non-specific (environmental) mycobacterial sensitization between the two. The characteristics of the two population groups and methods of testing and analysis were as described in the preceding paper on reactivity to lepromin A. ${ }^{1}$ The SPA used (batch CD 19), had a protein content of $10 \mu \mathrm{g} \mathrm{ml}^{-1}$, and the reaction was read as the maximum palpable transverse and vertical diameters of induration, at $72 \mathrm{~h}$.

An evaluation, using the regression analysis technique found that the transverse and vertical diameters of the SPA reaction were highly correlated. Hence in this study, the transverse reaction alone was used in further analysis.

\section{Results}

The frequency distributions of reactions to SPA in the two whole population groups, from the two different areas are presented in Figure 1. The overall

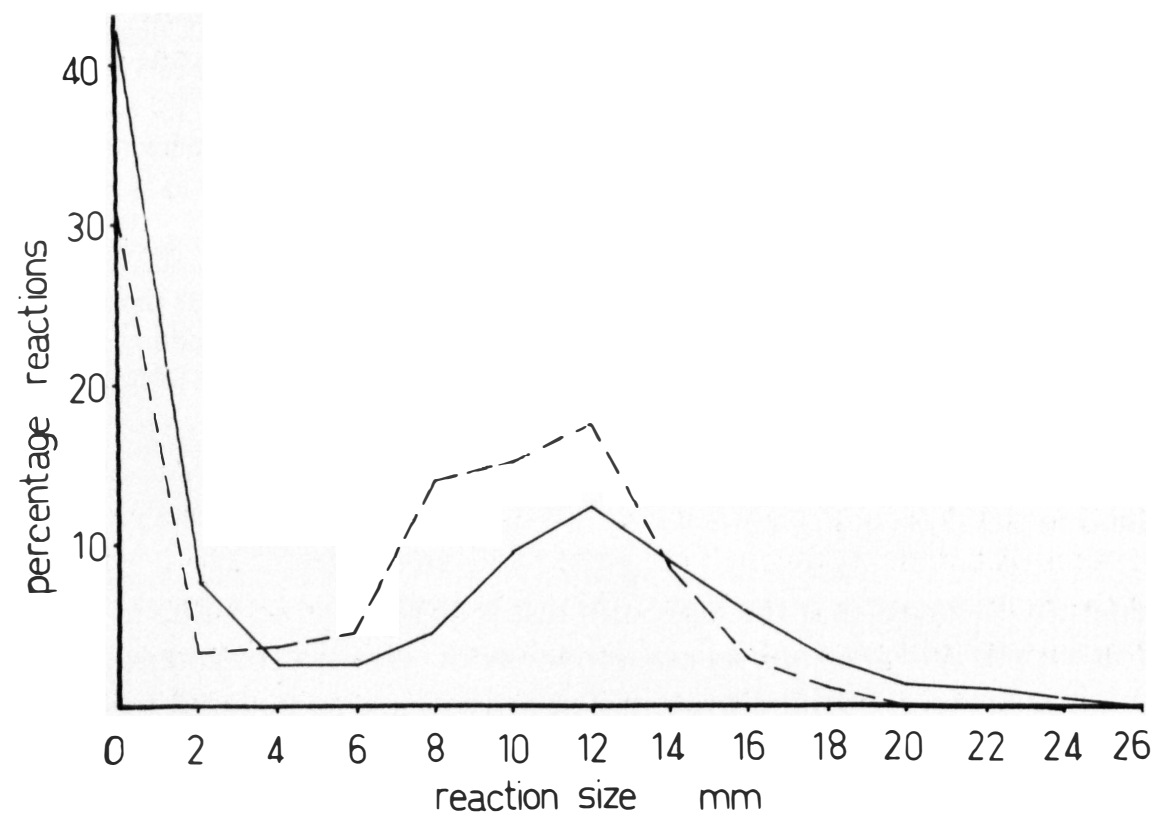

Figure 1. Frequency distributions of reactions to SPA of the two whole population groups; Mahagastota, ——; and Galagedera, ----. 


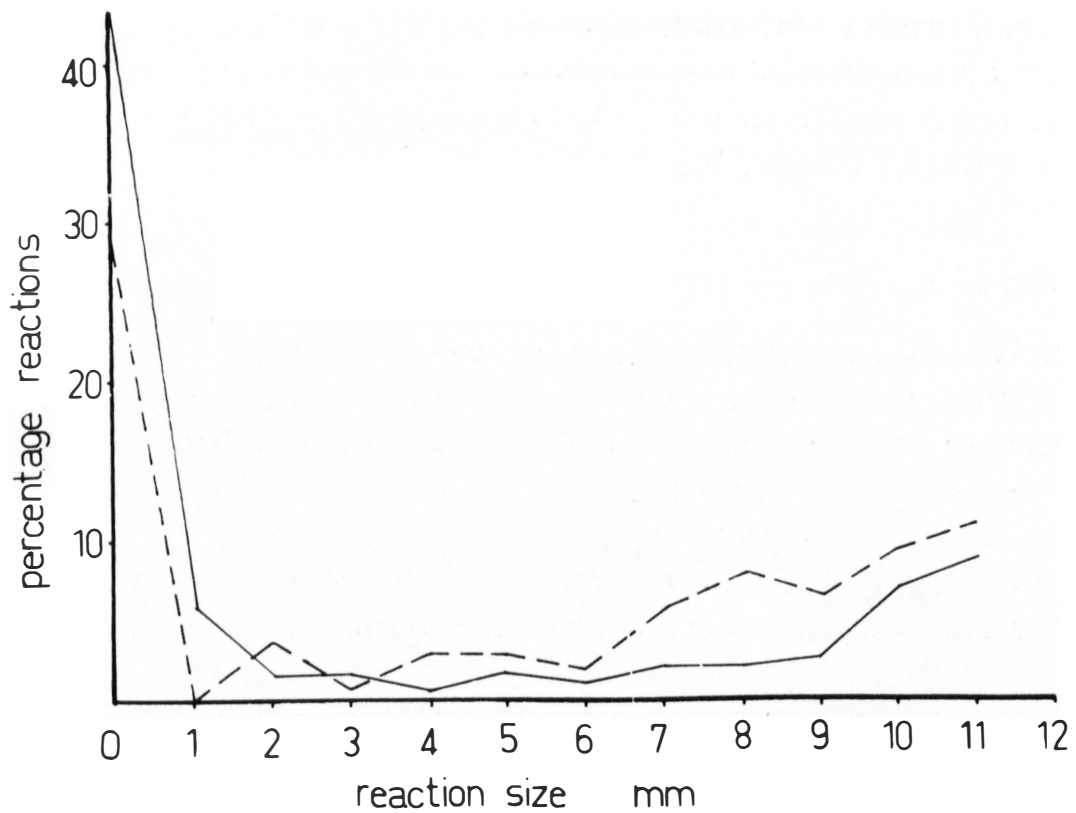

Figure 2. Frequency distribution of SPA reactions of $0-11 \mathrm{~mm}$ of the populations at Mahagastota $(-)$ and Galagedera (-- ).

patterns of distribution in the two groups seem to be more or less similar. In both groups, the distributions can be divided into a 'reactor' and 'nonreactor' component, the mode of the former being at around the $11-12 \mathrm{~mm}$ reaction size. As described in the preceding paper on lepromin sensitivity, an attempt was made to demarcate a reaction size at which we could best differentiate between the reactors ('positive') and nonreactors ('negative') (Figure 2). It was decided that this point would be at around $5 \mathrm{~mm}$ where the error of false classification would be perhaps the least.

The influence of age on reactivity to SPA was evaluated using the regression analysis technique: this showed that reactivity showed no significant change with age.

The influence of factors such as sex, BCG vaccination status and race on reactivity to SPA was also evaluated, where the numbers of individuals whose results were available, sufficed. The mean reaction sizes of the total distributions, and of the reactors are presented in Table 1 . Although the numbers of individuals in the different groups are small, some patterns could be identified. Thus males and the BCG vaccinated seem to have lesser numbers of nonreactors and also larger reactions than do females and the BCG not vaccinated. Such differences were not consistently demonstrable, however, between the two racial groups (Sinhalese and Indian Tamils). The frequency distributions of different groups or subsets of the populations were also compared using the $\chi$-square test to assess the 
Table 1. Means of reactions to SPA

\begin{tabular}{|c|c|c|}
\hline & \multicolumn{2}{|c|}{$\begin{array}{l}\text { Means of reactions } \\
\text { (numbers in } \\
\text { parentheses) }\end{array}$} \\
\hline & Total group & Reactors \\
\hline \multicolumn{3}{|c|}{ I. Mahagastota (Nuwara Eliya) } \\
\hline \multicolumn{3}{|c|}{ (A) $B C G$-ve } \\
\hline 1 Sinhalese males & $7 \cdot 67(3)$ & $11 \cdot 5(2)$ \\
\hline females & $6 \cdot 63(12)$ & $11 \cdot 84(6)$ \\
\hline 2 Tamil males & $5 \cdot 19(29)$ & $12 \cdot 17(12)$ \\
\hline females & $4 \cdot 01(111)$ & $11 \cdot 63(36)$ \\
\hline \multicolumn{3}{|l|}{ (B) $B C G+v e$} \\
\hline 1 Sinhalese males & $11 \cdot 25(6)$ & $13 \cdot 5(5)$ \\
\hline females & $9 \cdot 85(13)$ & $12 \cdot 5(10)$ \\
\hline 2 Tamil males & $11 \cdot 73(24)$ & $13 \cdot 41(21)$ \\
\hline females & $6 \cdot 31(63)$ & $11 \cdot 81(33)$ \\
\hline \multirow{2}{*}{\multicolumn{3}{|c|}{ II. Galagedara }} \\
\hline & & \\
\hline 1 Sinhalese males & $7 \cdot 64(22)$ & $10 \cdot 5(16)$ \\
\hline females & $4 \cdot 44(54)$ & $8 \cdot 76(27)$ \\
\hline 2 Tamil males & $7 \cdot 86(17)$ & $12 \cdot 14(11)$ \\
\hline females & $6.99(31)$ & $9.98(21)$ \\
\hline \multicolumn{3}{|l|}{ (B) $B C G+v e$} \\
\hline 1 Sinhalese males & $10 \cdot 2(18)$ & $11 \cdot 38(16)$ \\
\hline females & $5.95(43)$ & $10 \cdot 17(24)$ \\
\hline 2 Tamil males & $9 \cdot 38(12)$ & $11 \cdot 77(9)$ \\
\hline females & $8 \cdot 85(20)$ & $10 \cdot 21(17)$ \\
\hline
\end{tabular}

influence of variations such as sex, race and BCG vaccination status on reactivity to SPA. The results are presented in Table 2. It is seen that while, in general, sex, race and $B C G$ vaccination status, do not seem to produce any significant changes in reactivity to SPA, changes in geographical locality may do so.

Since it has been suggested that the Fernandez reaction to lepromin, may be an analogue of the tuberculin reaction, and also that SPA elicits a reaction, similar to the latter, a comparison of the patterns of reactivity of both may be of value (Figures 3(a) and (b) and 4(a) and (b). However, the patterns of reactivity shown by the two types of reactions is markedly different. The relationship between these two types of reactions could be examined further by the use of bivariate frequency distributions, but this will be evaluated in a subsequent paper (as will be its correlation to Mitsuda reactivity). 
Table 2. Influence of different biological variables on reactivity to SPA as evaluated by the $\chi$-square test

\begin{tabular}{lcccc} 
& & \multicolumn{3}{c}{$\begin{array}{c}\text { Number of groups showing changes } \\
\text { that were }\end{array}$} \\
& $\begin{array}{c}\text { Total No. of } \\
\text { groups } \\
\text { compared }\end{array}$ & $\begin{array}{c}\text { Not } \\
\text { Variable studied }\end{array}$ & $\begin{array}{c}\text { Significant } \\
\text { at 5\% level }\end{array}$ & $\begin{array}{c}\text { Significant } \\
\text { at } 1 \% \text { level }\end{array}$ \\
\hline $\begin{array}{l}\text { Sex } \\
\text { (male versus female) }\end{array}$ & 6 & 5 & - & 1 \\
$\begin{array}{l}\text { Race } \\
\text { (Sinhalese versus Indian Tamil) }\end{array}$ & 5 & 5 & - & - \\
$\begin{array}{l}\text { BCG vaccination } \\
\text { status. (Vaccinated }\end{array}$ & 6 & 5 & - & 1 \\
$\begin{array}{l}\text { vs. not vaccinated) } \\
\begin{array}{l}\text { Geographical area } \\
\text { (Mahagastota versus }\end{array}\end{array}$ & & & & 1 \\
Galagedera) & 6 & 3 & 2 & 1 \\
\hline
\end{tabular}

\section{Discussion}

There is little data on reactivity to SPA in the published literature, available for comparison, with the data here. The available data are mainly from studies on leprosy patients and their contacts, and have been reported to yield promising results from the point of view of its value in identifying those possibly infected with $M$. leprae. In the absence of more documentation on the specificity of the test, we did not attempt to identify the possible $M$. leprae infected in the populations we have investigated on the basis of the SPA reaction. The significance of the 'positive' reactor could have been further evaluated if the pattern of reactions to SPA in Sri Lankan leprosy patients, was also available.

The two populations studied were deliberately selected for differences in expected levels of 'nonspecific' mycobacterial sensitization (low in Nuwara Eliya (Mahagastota) and high at Galagedera). ${ }^{2}$ The patterns of SPA reactions in the two areas do not seem to show any marked differences, though with the $\chi$-square test, three of six groups compared showed significant differences. It would not be possible to draw definitive conclusions on the effects of nonspecific sensitization to SPA reactivity on the basis of this study.

In the populations studied, those with BCG vaccination, had been vaccinated many years earlier. On examining the incidence of nonreactors, and mean reactor 

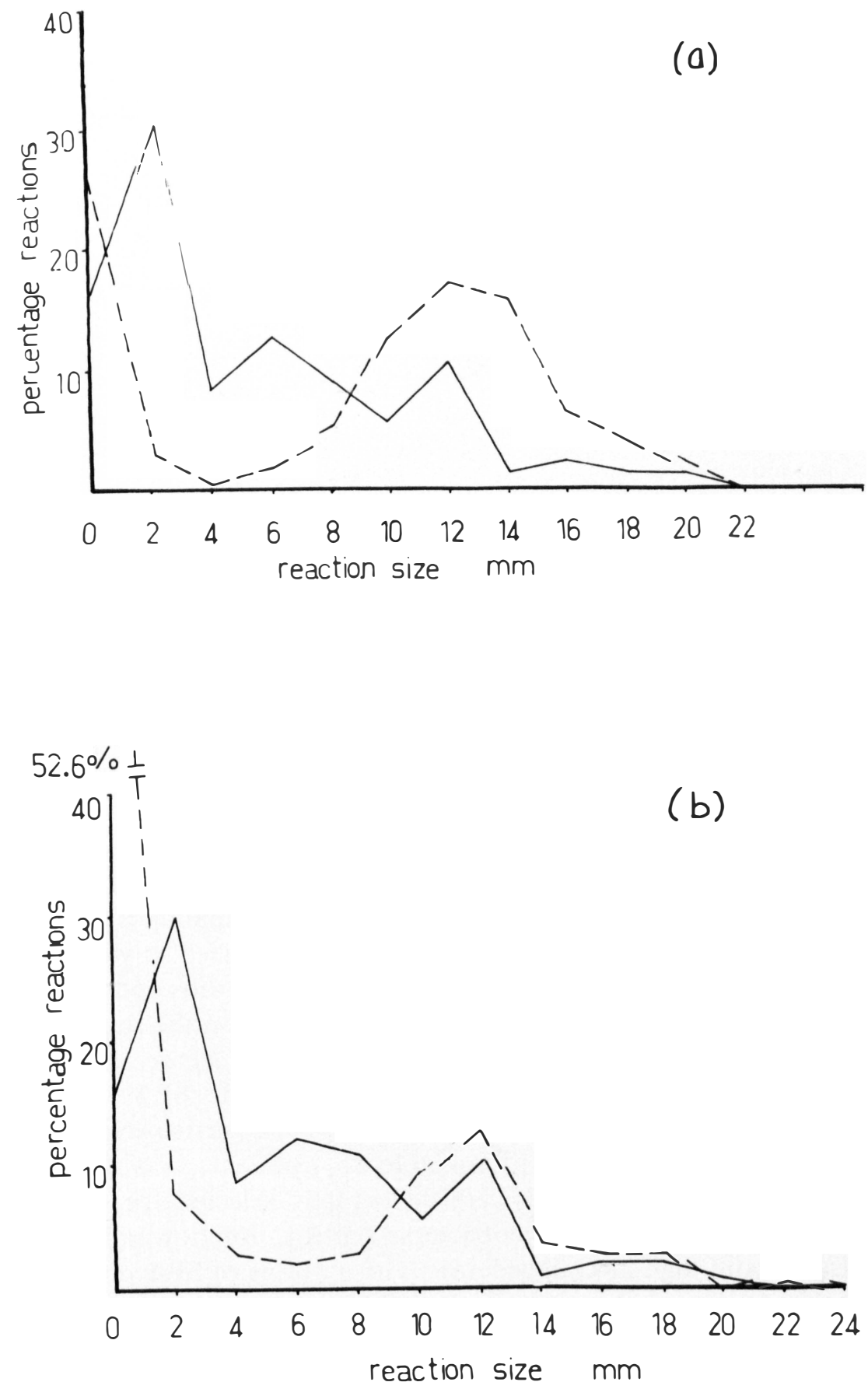

Figure 3.(a) Frequency distributions of SPA (-- ) and Fernandez (- - reactions of the BCG unvaccinated at Mahagastota. (b) Frequency distributions of SPA (-- ) and Fernandez ( - ) reactions of the BCG vaccinated at Mahagastota. 

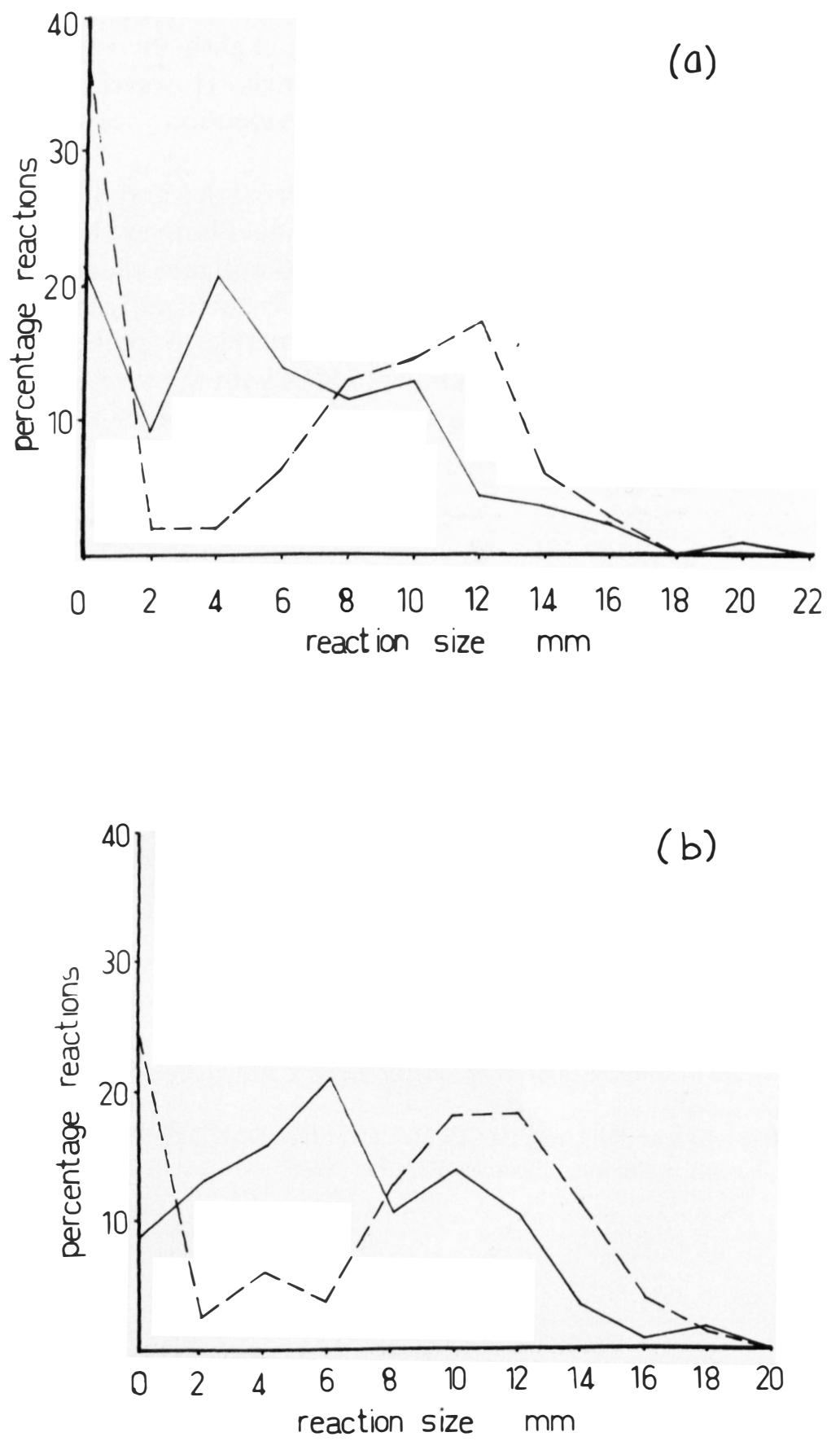

Figure 4.(a) Frequency distributions of SPA (-- ) and Fernandez (-) reactions of the BCG unvaccinated at Galagedera. (b) Frequency distributions of SPA (-- ) and Fernandez ( - ) reactions of the BCG vaccinated at Galagedera. 
sizes in these groups, the influence of BCG vaccination seems to have been to convert potential nonreactors to reactors, and to slightly increase the reaction size, the former being the more marked change. However, no markedly significant changes were found, on statistical evaluation, between the BCG vaccinated and those not so vaccinated.

The difference in reaction patterns between Fernandez and SPA reactivity is an interesting finding which poses the question whether both are being elicited by different antigens. Fernandez reactivity is elicited by antigens which are the whole bacteria, whereas in SPA reactivity, the internal cellular antigens, released by disruption of the cell bodies are also readily available to evoke reaction. An examination of the correlation of reactions to SPA with those of lepromin in the same individual could help in the evaluation of this relationship.

\section{Acknowledgments}

This investigation was supported in part by a grant from the Leprosy Section, World Health Organisation, Geneva.

We wish to thank Mr DW Dissanayake, Medical Assistant, Mahagastota State Plantation, Nuwara Eliya, and Ms MG Kusumalatha, Medical Assistant, Trafford Hill State Plantation, Galagedera, for assistance in carrying out this study; and Ms TM Gamage and Ms M Wijekoon of the Department of Microbiology, Faculty of Medicine, University of Peradeniya, Peradeniya, for assistance in data analysis.

\section{References}

I Pinto MRM, Eriyagama NB, Pemajayantha V. Studies of reactivity of some Sri Lankan population groups to antigens of Mycobacterium leprae: I. Reactivity to Lepromin A. Lepr Rev 1987; 58: 105-18.

2 Pinto MRM, Arseculeratne SN, Uragoda CG, Hemawardane DM. Differential tuberculin testing in rural populations in Ceylon. Tubercle 1972; 53: 182-97. 